\title{
DEPOSIÇÃO DE SERAPILHEIRA E DE NUTRIENTES NO SOLO EM SISTEMA AGROSSILVIPASTORIL COM EUCALIPTO E ACÁCIA ${ }^{1}$
}

Eliane Cristina Sampaio de Freitas ${ }^{2}$, Sílvio Nolasco de Oliveira Neto ${ }^{3}$, Dilermando Miranda da Fonseca ${ }^{4}$, Márcia Vitória Santos ${ }^{5}$, Helio Garcia Leite ${ }^{3}$ e Vitor Diniz Machado ${ }^{6}$

\begin{abstract}
RESUMO - Este estudo teve como objetivo avaliar o efeito do componente arbóreo no aporte de serapilheira e de nutrientes em dois Sistemas Agrossilvipastoris, sendo o sistema 1: milho (Zea mays) + eucalipto (híbrido - Eucalyptus grandis x E. urophylla) + acácia (Acacia mangium) + braquiária (Brachiaria decumbens); e o sistema 2: milho + eucalipto + braquiária, que foram comparados com monocultivo de pasto, em Viçosa, MG. A serapilheira do componente arbóreo e da forrageira foi coletada mensalmente, a partir dos 34 meses após a implantação, no período de outubro de 2010 a setembro de 2011, em distâncias a partir das linhas centrais do plantio das árvores, que consistiram nos subtratamentos: 1, 3 e $6 \mathrm{~m}$; e realizadas a análise e quantificação de nutrientes: N, P, K, Ca, Mg e S. A deposição da serapilheira da forrageira foi superior no monocultivo de pasto. Entretanto, a maior deposição de serapilheira total (forrageira + componente arbóreo) foi observada em ambos os sistemas agrossilvipastoris, comprovando a influência positiva do componente arbóreo no incremento de material vegetal depositado sobre o solo. A distância da linha de plantio das árvores também influenciou a deposição, que foi maior a $1 \mathrm{~m}$, seguida das distâncias 3 e $6 \mathrm{~m}$. Com exceção do P, os sistemas agrossilvipastoris depositaram maior quantidade de nutrientes por meio da serapilheira, destacando-se o sistema com acácia, que promoveu maior deposição de N. O componente arbóreo, a espécie leguminosa e a distância da linha de plantio das árvores dos sistemas agrossilvipastoris influenciaram a deposição de serapilheira e de nutrientes no solo, indicando a potencialidade desses sistemas para recuperação e manutenção de pastagens degradadas.
\end{abstract}

Palavras-chave: Sistemas agroflorestais; Ciclagem de nutrientes; Leguminosas.

\section{LITTER FALL AND NUTRIENT DEPOSITION ON SOIL IN AN AGROSILVOPASTORAL SYSTEM WITH EUCALYPT AND ACACIA}

\begin{abstract}
The objective of the present work was to evaluate the arboreal component effect on the allocation of litter and nutrients in two Agrosilvopastoral Systems, being System 1: maize (Zea mays) + eucalypt (Eucalyptus grandis $x$ E. urophylla hybrid) + acacia (Acacia mangium) + brachiaria grass (Brachiaria decumbens); System 2: maize + eucalypt + brachiaria grass; that were compared with pasture monoculture, in Viçosa, MG, Brazil. The litter of the arboreal component and of the forage was collected monthly, at 34 months after establishment, in the period from October 2010 to September 2011, and performed the analysis and quantification of $\mathrm{N}, \mathrm{P}, \mathrm{K}, \mathrm{Ca}, \mathrm{Mg}$ and $\mathrm{S}$. Litter deposition from the forage was higher in the pasture monoculture when compared with the associated systems. Nevertheless, the greater deposition of total litter (forage + arboreal component) was observed in the Agrosilvopastoril Systems, proving the positive influence of the arboreal component on the vegetal material increment laid on the soil. The planting line distance of the trees also influenced the litter deposition which was greater at $1 \mathrm{~m}$, compared with the distances of $3 \mathrm{~m}$, which was higher than $6 \mathrm{~m}$. Except for P, the Agrosilvopastoral Systems deposited a greater amount of nutrients from
\end{abstract}

\footnotetext{
${ }^{1}$ Recebido em 20.06.2012 aceito para publicação em 24.05.2013.

${ }^{2}$ Programa de Pós-Graduação em Ciência Florestal na Universidade Federal de Viçosa, UFV, Brasil. E-mail: <eliane.freitas@ufv.br>.

${ }^{3}$ Departamento de Engenharia Florestal da Universidade Federal de Viçosa, UFV, Brasil. E-mail: <snolasco@ufv.br> e<hgleite@ufv.br>.

${ }^{4}$ Departamento de Zootecnia da Universidade Federal de Viçosa, UFV, Brasil. E-mail: <dfonseca@ufv.br>.

${ }^{5}$ Departamento de Zootecnia da Universidade Federal dos Vales do Jequitinhonha e Mucuri, UFVJM, Brasil. E-mail: <marcia.vitoria@ufvjm.edu.br>.

${ }^{6}$ Programa de Pós-Graduação em Zootecnia na Universidade Federal de Viçosa, UFV, Brasil. E-mail: <vitordm_zootec@yahoo.com.br>.
} 
the system with from the litter, notably from the system with acacia that promoted a greater amount of nitrogen. The arboreal component, the leguminosae specie and the planting line distance influenced the litter and nutrient deposition on the soil in the Agrosilvopastoral Systems, indicating the potentiality of these systems to the recovery and maintenance of degraded pastures.

Keywords: Agroforestry systems; Nutrient cycling; Leguminosae.

\section{INTRODUÇÃO}

O processo de degradação de pastagens é considerado um dos maiores problemas da pecuária brasileira, uma vez que esse setor tem o pasto como base de sustentação (PERON; EVANGELISTA, 2004). Entre as várias causas da degradação, têm-se a má formação do pasto, o manejo e manutenção inadequados e o excesso de lotação (MACEDO, 2005). Na Zona da Mata mineira, o manejo inadequado das pastagens e a baixa fertilidade natural dos solos são os principais fatores que contribuem para a redução da produtividade, culminando em solos descobertos e infestados por plantas daninhas ou por gramíneas de baixo valor forrageiro (NASCIMENTO et al., 2006). A evolução desse processo pode resultar em compactação do solo, diminuição da infiltração e da capacidade de retenção da água, favorecendo a ocorrência de erosão e assoreamento dos cursos d'água (MACEDO, 2005).

Diante o interesse de recuperar a capacidade produtiva das pastagens, os Sistemas Agrossilvipastoris surgem como alternativa potencial, principalmente, para pequenos e médios produtores, uma vez que podem elevar e diversificar a renda, adicionando benefícios ambientais às atividades produtivas. Com a utilização dos Sistemas Agroflorestais (SAFs), o uso da terra pode ser otimizado e o impacto causado por práticas agrícolas, reduzido, diante o potencial de o componente arbóreo promover a conservação do solo e da água e favorecer a ciclagem de nutrientes por meio do maior aporte de serapilheira (LIMA et al., 2007; BERNARDINO; GARCIA, 2009).

A introdução de árvores na pastagem pode influenciar a quantidade e disponibilidade de nutrientes na zona de absorção radicular das culturas consorciadas. Isso ocorre porque o sistema radicular das árvores, por ser mais profundo, intercepta os nutrientes localizados em camadas do solo pouco acessíveis às raízes das forrageiras e os disponibiliza na sua superfície à medida que seu material vegetativo é depositado e decomposto (CASTRO et al., 1996; SÁNCHEZ et al., 2003).
A serapilheira é fundamental para a autossustentabilidade dos ecossistemas florestais. Inicia o primeiro estágio de transferência de nutrientes para o sistema, em que grande parte dos nutrientes absorvidos pela vegetação retorna ao solo através da sua deposição (CALDEIRA et al., 2008). Essa dinâmica da serapilheira, representada pela entrada via deposição e saída via decomposição/mineralização, é fundamental para a manutenção da ciclagem de nutrientes (BALIEIRO et al., 2004). Isso é evidenciado pelas florestas que se mantêm em áreas com solos de baixa fertilidade (SCHUMACHER et al., 2003). Além disso, a serapilheira reduz a incidência da radiação solar direta sobre o solo e, consequentemente, favorece a retenção de umidade (JARAMILLO-BOTERO et al., 2008).

Para que a ciclagem de nutrientes ocorra é necessária, entretanto, a decomposição do material vegetativo depositado sobre o solo. Maiores taxas de decomposição favorecem a liberação mais rápida de nutrientes e o seu melhor reaproveitamento por parte da vegetação do sistema (ARATO et al., 2003). A taxa de decomposição da serapilheira é influenciada por vários fatores, entre eles pela relação $\mathrm{C} / \mathrm{N}$ do material que a compõe. Essa relação quando é baixa favorece a decomposição da serapilheira, porque a quantidade de $\mathrm{N}$ nela influencia a velocidade da sua decomposição, ou seja, resíduos com alta relação $\mathrm{C} / \mathrm{N}$ demoram mais para serem decompostos (MARQUES et al., 2000).

Nesse sentido, a presença de leguminosas arbóreas com potencial para fixação biológica de nitrogênio nos Sistemas Agrossilvipastoris é favorável porque elas podem diminuir a relação $\mathrm{C} / \mathrm{N}$ da serapilheira (GARAY et al., 2003), favorecer o processo de decomposição (GARCIA et al., 2010), melhorar a fertilidade do solo (KHANNA, 1998; FORRESTER et al., 2006) e contribuir para a manutenção e elevação da produtividade das pastagens (XAVIER et al., 2003; PACIULLO et al., 2003; POWER et al., 2003). Além disso, o aproveitamento do solo no consórcio de uma leguminosa arbórea com

Revista Árvore, Viçosa-MG, v.37, n.3, p.409-417, 2013 
outras espécies pode ser mais eficiente devido às diferenças no sistema radicular e nas exigências nutricionais (KLEINPAUL et al., 2010).

Nesse contexto, a espécie Acacia mangium destaca-se como opção silvicultural em sistemas consorciados, sobretudo em áreas com solos de baixa fertilidade, devido ao seu potencial para produção de madeira com baixo acúmulo de nutrientes (BALIEIRO et al., 2004) e de fixação biológica de nitrogênio, que, além de favorecer a ciclagem desses nutrientes, incorpora o $\mathrm{N}$ no solo para absorção por outras culturas (WILDIN, 1990).

Este estudo teve como objetivo avaliar o efeito do eucalipto e do eucalipto com acácia no aporte de serapilheira e de nutrientes em Sistema Agrossilvipastoril em Viçosa, MG.

\section{MATERIAL E MÉTODOS}

\subsection{Caracterização da área experimental}

O estudo foi realizado no Município de Viçosa, MG, localizado a $20^{\circ} 46^{\prime}$ de latitude Sul e $42^{\circ} 51^{\prime}$ de longitude Oeste, a $689 \mathrm{~m}$ de altitude, em área de pastagem recuperada através de Sistema Agrossilvipastoril, utilizando o Sistema de Plantio Direto (SPD). O solo da área experimental é um Latossolo Vermelho-Amarelo de textura argilosa, em relevo medianamente ondulado (SANTOS, 2009). Antes da implantação desse sistema, em dezembro de 2007, realizou-se a amostragem de solo, na camada de 0-20 cm, cujas características químicas foram: $\mathrm{pH}$ em $\mathrm{H}_{2} \mathrm{O}: 5,60$; P: 1,13 $\mathrm{mg} \mathrm{dm}^{-3}$ (Mehlich) e $\mathrm{K}: 41,00 \mathrm{mg} \mathrm{dm}^{-3} ; \mathrm{Ca}^{+2}: 3,33 ; \mathrm{Mg}^{+2}: 0,57 \mathrm{e} \mathrm{Al}^{+3}$ : $0,03 \mathrm{cmol} \mathrm{dm}_{\mathrm{c}}^{-3}\left(\mathrm{KCl} 1 \mathrm{~mol} \mathrm{~L}^{-1}\right), \mathrm{CTC}(\mathrm{T}): 5,99 \mathrm{cmol} \mathrm{dm}_{\mathrm{c}}^{-3}$, soma de bases: $2,34 \mathrm{cmol}_{\mathrm{c}} \mathrm{dm}^{-3}, \mathrm{H}+\mathrm{Al}: 3,65 \mathrm{cmol}_{\mathrm{c}} \mathrm{dm}^{-3}$ e 2,37 dag $\mathrm{kg}^{-1}$ de matéria orgânica e 20,35 de P-rem.

Segundo a classificação de Köppen, o clima na região de Viçosa é do tipo Cwb, mesotérmico com verões quentes e chuvosos e invernos frios e secos. A temperatura média anual é de $19,4^{\circ} \mathrm{C}$ e a precipitação pluviométrica média anual, de $1.221 \mathrm{~mm}$ (DNMET, 1992).

\subsection{Caracterização do experimento}

O experimento foi realizado em dois Sistemas Agrossilvipastoris, sendo o Sistema 1: milho (Zea mays) + eucalipto (híbrido-Eucalyptus grandis x E. urophylla) + acácia (Acacia mangium) + braquiária (Brachiaria decumbens); e o Sistema 2: milho (Zea mays) + eucalipto
(híbrido-Eucalyptus grandis x E. urophylla); mais testemunha: braquiária (Brachiaria decumbens) em monocultivo, conforme Santos (2009).

As parcelas dos tratamentos em consórcio possuíam dimensões de $24 \mathrm{~m}$ de largura por $12 \mathrm{~m}$ de comprimento, totalizando uma área de $288 \mathrm{~m}^{2}$, composta por três fileiras de eucalipto ou eucalipto + acácia, alternadas nas linhas de plantio, que foram espaçadas a cada $12 \mathrm{~m}$, com $2 \mathrm{~m}$ entre plantas. As parcelas de pasto em monocultivo possuíam $24 \mathrm{~m}$ de largura por $10 \mathrm{~m}$ de comprimento, totalizando uma área de $240 \mathrm{~m}^{2}$.

O milho e a braquiária foram semeados em dezembro de 2007, entre as fileiras das espécies arbóreas, através do Sistema de Plantio Direto, após a dessecação e calagem do pasto degradado. $\mathrm{O}$ milho foi cultivado apenas no primeiro ano de implantação do sistema, no espaçamento de $0,8 \mathrm{~m}$ entre linhas, e a espécie forrageira, no espaçamento de $0,4 \mathrm{~m}$, sendo semeadas na linha e entrelinha do milho. Utilizaram-se $4 \mathrm{~kg} \mathrm{ha}^{-1}$ de sementes de braquiária, com seis sementes por metro linear de milho.

Após a colheita do milho, as plantas forrageiras das parcelas consorciadas e em monocultivo foram cortadas a $15 \mathrm{~cm}$ do nível do solo, para uniformização. A área foi manejada sem a presença de animais até um ano de implantação do sistema (dezembro de 2008). Posteriormente, o pastejo foi realizado em ciclos baseados no percentual de interceptação de luminosidade, ou seja, quando a espécie forrageira estava interceptando $95 \%$ da radiação solar, conforme Wendling (2011), ocasião em que os animais eram inseridos na área para o pastejo até a forragem residual atingir 15 a $20 \mathrm{~cm}$ de altura.

\subsection{Avaliação da serapilheira}

O delineamento experimental utilizado foi em blocos casualizados com três repetições e parcelas subdivididas, sendo dois tratamentos (Sistema Agrossilvipastoril com eucalipto e Sistema Agrossilvipastoril com eucalipto + acácia) e três subtratamentos (distâncias a partir de linhas centrais de plantio das árvores 1, 3 e 6 m), além de uma testemunha (pasto em monocultivo).

Para avaliação da deposição de serapilheira do componente arbóreo (eucalipto e acácia), foram coletados materiais vegetais em caixas de madeira com dimensões de 60 × 35 × $30 \mathrm{~cm}$ (comprimento x largura x altura), compondo área de $0,21 \mathrm{~m}^{2}$ cada, com sombrite em sua

Revista Árvore, Viçosa-MG, v.37, n.3, p.409-417, 2013 
base interna. Com o objetivo de verificar a influência da distância das árvores na deposição da serapilheira no Sistema Agrossilvipastoril, coletores foram dispostos nas distâncias dos subtratamentos, com quatro repetições.

As coletas foram realizadas mensalmente, a partir de 34 meses após a implantação, durante o período de um ano, entre outubro de 2010 e setembro de 2011 , nos períodos de pousio da pastagem, que foi manejada através de sistema rotacionado. Nos períodos de pousio, as caixas coletoras eram distribuídas na área experimental, visando eliminar possíveis danos que poderiam ser causados pelos animais sobre as estruturas coletoras. As caixas foram distribuídas em pontos fixos dispostos aleatoriamente, adotando-se quatro repetições por tratamento, tanto nos Sistemas Agrossilvipastoris quanto na pastagem em monocultivo. O material coletado nos dias de pousio foi, então, extrapolado para 30 dias, a fim de obter o valor da deposição mensal, conforme Xavier et al. (2011).

A serapilheira da forrageira, composta de materiais vegetais depositados sobre o solo, foi coletada manualmente na superfície do solo, segundo metodologia de Santos et al. (2007), utilizando-se quadrantes de $0,25 \mathrm{~m}^{2}$.

Para determinação do peso de matéria seca, as amostras de serapilheira foram condicionadas em sacolas de papel e secas em estufa de circulação e renovação de ar, a $65^{\circ} \mathrm{C}$, por $72 \mathrm{~h}$, e depois pesadas em balança de precisão $(0,01 \mathrm{~g})$.

A produção mensal de serapilheira foi calculada segundo a fórmula:

$$
\mathrm{PS}=((\text { Pse }- \text { Psaq }) \times 30) / \mathrm{d}) \times 10.000 / \mathrm{AC}
$$

em que:

- PS: produção média mensal de serapilheira $\left(\mathrm{kg} \mathrm{ha}^{-1}\right.$ mês $\left.{ }^{-1}\right)$;

- Pse: peso da amostra seca em estufa (g);

- Psaq: peso do saco de papel (g);

- d: dias de coleta em um mês; e

- AC: área do coletor $\left(\mathrm{m}^{2}\right)$

Depois de obtida a produção mensal de serapilheira, as amostras foram trituradas em moinho tipo Wiley e submetidas à digestão nitroperclórica.
Posteriormente, foi elaborada a solução mineral para leitura dos nutrientes $\mathrm{K}, \mathrm{P}, \mathrm{Mg}$, Ca e S, no Laboratório de Solos Florestais, do Departamento de Solos da Universidade Federal de Viçosa (UFV), em Viçosa, MG. O teor de $\mathrm{N}$ total foi quantificado pelo método de "Kjeldhal", conforme metodologias descritas por Tedesco et al. (1995).

As deposições de serapilheira e do conteúdo de nutrientes foram analisadas entre os tratamentos, sendo as médias, no caso de haver diferenças significativas, comparadas pelo teste de Tukey a 5\% de significância. O efeito das distâncias das linhas de plantio das árvores foi avaliado através do ajuste de regressão não linear.

\section{RESULTADOS}

A deposição de serapilheira pela forrageira foi superior no monocultivo de pasto, em comparação com os sistemas consorciados (Tabela 1). Entretanto, a maior deposição de serapilheira total (forrageira + componente arbóreo) foi observada nos Sistemas Agrossilvipastoris, em comparação com o monocultivo. As distâncias da linha de plantio das árvores influenciaram a quantidade de serapilheira do componente arbóreo depositada nos Sistemas Agrossilvipastoris (Figura 1), sendo observada relação inversamente proporcional entre a deposição e as distâncias das árvores.

O teor médio de nutrientes na serapilheira da forrageira não diferenciou estatisticamente entre os Sistemas Agrossilvipastoris e a monocultura de pasto, exceto o teor de cálcio, que foi maior no sistema com eucalipto e acácia (Tabela 2). Na serapilheira do

Tabela 1 - Produção de serapilheira total em monocultura de pasto (MP), em Sistema Agrossilvipastoril com eucalipto (SASP-E) e com eucalipto e acácia (SASP-EA).

Table 1 - Total litter production in pasture monoculture (MP), in Agrosilvopastoral System with eucalypt (SASP-E) and with eucalypt and acacia ( $S A S P-E A)$.

\begin{tabular}{lccc}
\hline \multirow{2}{*}{ Tratamento } & \multicolumn{3}{c}{ Serapilheira $\left(\mathrm{kg} \mathrm{ha}^{-1} \mathrm{ano}^{-1}\right)$} \\
\cline { 2 - 5 } & $\begin{array}{c}\text { Componente } \\
\text { arbóreo }\end{array}$ & Forrageira & Total \\
\hline MP & - & $2.387,64 \mathrm{a}$ & $2.387,64 \mathrm{~b}$ \\
SASP-E & $2.863,96 \mathrm{a}$ & $1.355,83 \mathrm{ab}$ & $4.219,80 \mathrm{a}$ \\
SASP-EA & $3.678,09 \mathrm{a}$ & $772,02 \mathrm{~b}$ & $4.450,11 \mathrm{a}$ \\
\hline
\end{tabular}

Médias seguidas de mesma letra na coluna não diferem estatisticamente entre si, pelo teste de Tukey a $5 \%$.

Revista Árvore, Viçosa-MG, v.37, n.3, p.409-417, 2013 


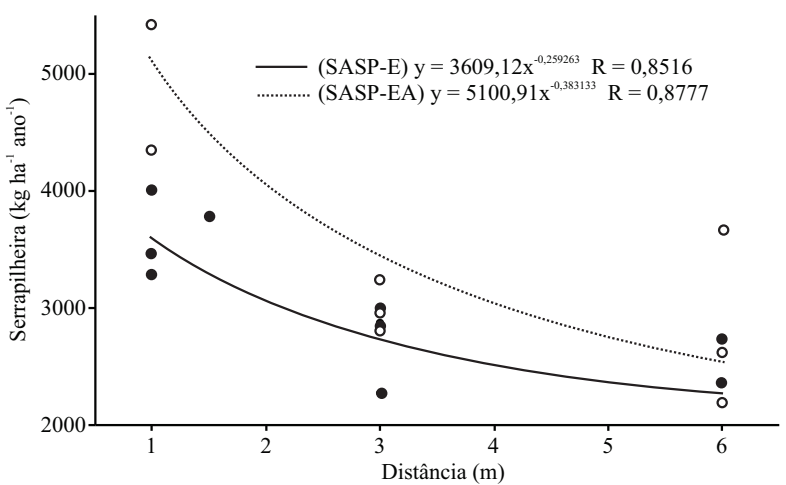

Figura 1 - Produção de serapilheira total no Sistema Agrossilvipastoril com eucalipto (SASP-E) e com eucalipto e acácia (SASP-EA), em função das distâncias da linha de plantio das árvores.

Figure 1 - Total litter production in the Agrosilvopastoral System with eucalypt (SASP-E) and with eucalypt and acacia (SASP-EA), in function of the tree distance planting rows. componente arbóreo, a exceção ocorreu com o teor de nitrogênio, que foi maior no Sistema Agrossilvipastoril com acácia.

À exceção do $\mathrm{P}$, os Sistemas Agrossilvipastoris foram os que mais depositaram nutrientes no solo através da serapilheira (Tabela 3). Entre esses sistemas, destacou-se aquele com acácia, que promoveu maior deposição de nitrogênio.

\section{DISCUSSÃO}

A maior deposição de serapilheira da forrageira na monocultura de pasto é justificada pela maior produção de matéria seca de forragem verde $\left(8.208,36 \mathrm{~kg} \mathrm{ha}^{-1} \mathrm{ano}^{-1}\right)$, em comparação com os Sistemas Agrossilvipastoris com eucalipto e acácia $\left(4.919,30 \mathrm{~kg} \mathrm{ha}^{-1} \mathrm{ano}^{-1}\right)$ e com eucalipto (3.870,16 kg ha-1 ano $^{-1}$ ) (WENDLING, 2011), uma vez que na ausência de sombreamento há tendência de

Tabela 2 - Teor médio de nutrientes na serapilheira da forrageira e do componente arbóreo, em monocultura de pasto (MP) e em Sistema Agrossilvipastoril com eucalipto (SASP-E) e com eucalipto e acácia (SASP-EA).

Table 2 -Average content of nutrients in the litter of the forage and of the arboreal component, in pasture monoculture $(M P)$ and Agrosilvopastoral System with eucalypt (SASP-E) and with eucalypt and acacia (SASP-EA).

\begin{tabular}{ccccccc}
\hline \multirow{2}{*}{ Tratamento } & $\mathrm{P}$ & $\mathrm{K}$ & $\mathrm{Ca}$ & $\mathrm{Mg}$ & $\mathrm{S}$ \\
\cline { 2 - 7 } & \multicolumn{7}{c}{$\left(\mathrm{g} \mathrm{kg}^{-1}\right)$} \\
\cline { 2 - 7 } & $0,68 \mathrm{a}$ & $2,70 \mathrm{a}$ & $3,04 \mathrm{~b}$ & $1,80 \mathrm{a}$ & $0,74 \mathrm{a}$ & $14,66 \mathrm{a}$ \\
\cline { 2 - 7 } & $0,55 \mathrm{a}$ & $2,75 \mathrm{a}$ & $3,35 \mathrm{ab}$ & $1,49 \mathrm{a}$ & $0,75 \mathrm{a}$ & $14,73 \mathrm{a}$ \\
SASP-E & $0,47 \mathrm{a}$ & $2,78 \mathrm{a}$ & $3,72 \mathrm{a}$ & $1,74 \mathrm{a}$ & $0,76 \mathrm{a}$ & $13,53 \mathrm{a}$ \\
\hline SASP-EA & $0,08 \mathrm{a}$ & $2,03 \mathrm{a}$ & $7,07 \mathrm{a}$ & $1,41 \mathrm{a}$ & $0,49 \mathrm{a}$ & $8,67 \mathrm{~b}$ \\
\hline SASP-E & $0,03 \mathrm{a}$ & $1,88 \mathrm{a}$ & $7,09 \mathrm{a}$ & $1,32 \mathrm{a}$ & $0,53 \mathrm{a}$ & $10,90 \mathrm{a}$ \\
\hline SASP-EA & &
\end{tabular}

Médias seguidas de mesma letra na coluna, por tipo de serapilheira, não diferem estatisticamente entre si, pelo teste de Tukey a $5 \%$.

Tabela 3 - Conteúdo de nutrientes na serapilheira total, em monocultura de pasto (MP) e em sistema Agrossilvipastoril com eucalipto (SASP-E) e com eucalipto e acácia (SASP-EA).

Table 3 - Amount of nutrients in the total litter in pasture monoculture (MP) and Agrosilvopastoral System with eucalypt (SASP-E) and with eucalypt and acacia (SASP-EA).

\begin{tabular}{|c|c|c|c|c|c|c|}
\hline \multirow{2}{*}{ Tratamento } & $\mathrm{P}$ & $\mathrm{K}$ & $\mathrm{Ca}$ & $\mathrm{Mg}$ & $\mathrm{S}$ & $\mathrm{N}$ \\
\hline & \multicolumn{6}{|c|}{$\left(\mathrm{kg} \mathrm{ha}^{-1} \mathrm{ano}^{-1}\right)$} \\
\hline MP & $1,62 \mathrm{a}$ & $6,45 \mathrm{~b}$ & $7,26 \mathrm{c}$ & $4,30 \mathrm{~b}$ & $1,77 \mathrm{~b}$ & $35,00 \mathrm{c}$ \\
\hline SASP-E & $0,97 \mathrm{ab}$ & $9,54 \mathrm{a}$ & $24,79 \mathrm{~b}$ & 6,06 a & $2,42 \mathrm{ab}$ & $44,80 \mathrm{~b}$ \\
\hline SASP-EA & $0,47 \mathrm{~b}$ & $9,06 \mathrm{a}$ & $28,95 \mathrm{a}$ & $6,20 \mathrm{a}$ & $2,54 \mathrm{a}$ & $50,54 \mathrm{a}$ \\
\hline
\end{tabular}

Médias seguidas de mesma letra na coluna não diferem estatisticamente entre si, pelo teste de Tukey a $5 \%$. 
maior produção de biomassa das gramíneas e, provavelmente, maior deposição de serapilheira. Apesar de não haver diferenças estatísticas, a deposição de serapilheira da forrageira no Sistema Agrossilvipastoril com eucalipto foi superior à do sistema com eucalipto e acácia. Tal fato, provavelmente, se deve ao maior sombreamento promovido pela presença da acácia, que apresentava menor crescimento, com o dossel ocupando estrato inferior ao do eucalipto, ao contrário do sistema que possuía somente o eucalipto, em que o estrato inferior se mantinha menos sombreado. Paciullo et al. (2007) observaram que, em condições de sombreamento intenso, os valores de massa de forragem, densidade de perfilho e índice de área foliar da Brachiaria decumbens foram menores em comparação com os valores a pleno sol.

O maior aporte de serapilheira total durante o período de estudo foi, contudo, observado nos Sistemas Agrossilvipastoris com eucalipto (4.219,80 $\mathrm{kg} \mathrm{ha}^{-1} \mathrm{ano}^{-1}$ ) e com eucalipto mais acácia $(4.450,11$ $\mathrm{kg} \mathrm{ha}^{-1} \mathrm{ano}^{-1}$ ), comparados à monocultura de pasto (2.387,64 kg ha-1 $\left.\mathrm{ano}^{-1}\right)$, evidenciando-se a contribuição significativa do componente arbóreo para o aumento da quantidade de material vegetal depositado sobre o solo. Em Sistema Silvipastoril, na Zona da Mata de Minas Gerais, Xavier et al. (2011) também observaram efeito adicional das árvores na deposição de serapilheira (5.038 kg ha-1 ano $\left.{ }^{-1}\right)$, em comparação com o monocultivo de pasto $\left(3.944 \mathrm{~kg} \mathrm{ha}^{-1} \mathrm{ano}^{-1}\right)$. Esses resultados indicaram a maior eficiência dos Sistemas Agrossilvipastoris para a deposição de material vegetal no solo, em comparação com as monoculturas. Por essa razão, as espécies arbóreas consorciadas com forrageiras podem contribuir com a recuperação de pastagens degradadas. A maior ciclagem de nutrientes proporcionada pelas árvores é considerada indicador biofísico de sustentabilidade dos Sistemas Agroflorestais (DANIEL et al., 2001).

Nesse contexto, a escolha da distância das linhas de plantio das árvores no Sistema Agrossilvipastoril, ou Silvipastoril, pode ser estratégia importante para otimizar o aproveitamento dos nutrientes advindos da serapilheira. Os resultados indicaram relação inversamente proporcional entre a deposição de serapilheira e a distância das árvores. Dias et al. (2006) verificaram maiores produções de massa seca e acúmulo de nutrientes no capim-survenola, em sistemas consorciados com leguminosas arbóreas, a $50 \mathrm{~cm}$ do tronco e na metade da projeção das copas das árvores. Isso reforça a importância sobre a disposição das árvores nos Sistemas Agrossilvipastoris, uma vez que há estudos que indicam que a qualidade da forragem tende a melhorar nas áreas mais próximas às suas copas (XAVIER et al., 2003; DIAS et al., 2007).

$\mathrm{Na}$ serapilheira do componente arbóreo foi observado maior teor de nitrogênio no Sistema Agrossilvipastoril com eucalipto e acácia, em comparação com o sistema que possui apenas eucalipto. O mesmo foi observado por Vezzani et al. (2001) e Forrester et al. (2004), que concluíram que o estoque de nitrogênio aumentou em plantios consorciados de eucalipto e acácia-negra, comparados ao monocultivo de eucalipto. Em monocultura de Acacia mangium, estabelecida no espaçamento 3 x $1 \mathrm{~m}$, Balieiro et al. (2004) observaram teor de $\mathrm{N}$ na serapilheira de $19,7 \mathrm{~g} \mathrm{~kg}^{-1}$, comparados aos $10,90 \mathrm{~g} \mathrm{~kg}^{-1}$ encontrados na serapilheira do Sistema Agrossilvipastoril com acácia, neste estudo.

Esses resultados evidenciam a importância da escolha das espécies arbóreas que compõem os sistemas consorciados, já que a deficiência de $\mathrm{N}$ é uma das principais causas que levam à degradação das pastagens, sendo esse nutriente o maior limitante da produtividade destas (GALZERANO; MORGADO, 2007; COSTA et al., 2008). Devido ao potencial econômico e custo dos fertilizantes, plantios mistos com espécies fixadoras de N surgem como opção para melhorar a fertilidade do solo no médio e no longo prazo (LACLAU et al., 2008), aumentando a disponibilidade de $\mathrm{N}$ e contribuindo para o maior rendimento das pastagens (POWER et al., 2003). Nesse sentido, destaca-se a escolha de espécies leguminosas com potencial de fixação biológica de nitrogênio para integrar os sistemas consorciados com o propósito de elevar a disponibilidade de $\mathrm{N}$ para a forrageira através da decomposição do material depositado sobre o solo. Todavia, além dos possíveis benefícios proporcionados pala fixação de nitrogênio, outros fatores devem ser considerados na escolha de espécies florestais para sistemas consorciados, como o potencial de produção, arquitetura da parte aérea e do sistema radicular, assim como o arranjo espacial e temporal dessas espécies.

Neste estudo, até o momento, a expectativa de contribuição da fixação biológica de nitrogênio pela Acacia mangium para a espécie forrageira não foi observada. O teor médio de nitrogênio na serapilheira

Revista Árvore, Viçosa-MG, v.37, n.3, p.409-417, 2013 
da forrageira não diferenciou entre o Sistema Agrossilvipastoril com acácia e a monocultura de pasto, o que pode ser justificado pela baixa velocidade da decomposição da serapilheira da acácia (BALIEIRO et al., 2004). No entanto, estudos recentes em Sistemas Agroflorestais comprovam o potencial da transferência do $\mathrm{N}$ fixado pelas leguminosas para as forrageiras. Sierra e Daudin (2010) observaram que, em média, 33\% do N encontrado na forrageira foi derivado da fixação biológica realizada pelas árvores. Valores similares foram obtidos por Dias et al. (2007) no capim-survenola, sob a influência das copas de leguminosas arbóreas com 9 anos de idade.

Diante o exposto, a consorciação de espécies leguminosas com potencial para fixação biológica de nitrogênio com espécies forrageiras pode ser alternativa viável para aumentar o aporte de $\mathrm{N}$ no sistema e favorecer a produção de forragem com a diminuição da demanda de insumos nitrogenados. Todavia, estudos sobre a taxa de decomposição da serapilheira e sobre a eficiência de absorção e utilização do nitrogênio oriundo da fixação e ciclagem de nutrientes devem ser complementares às informações aqui apresentadas.

\section{CONCLUSÕES}

O componente arbóreo, a espécie leguminosa e a distância da linha de plantio das árvores influenciaram a deposição de serapilheira e de nutrientes sobre o solo nos Sistemas Agrossilvipastoris. O maior aporte de serapilheira e de nutrientes, especificamente $\mathrm{N}$, no Sistema Agrossilvipastoril com eucalipto e acácia sugere seu maior potencial para recuperação e manutenção de pastagens.

\section{AGRADECIMENTOS}

À Fundação de Amparo à Pesquisa do Estado de Minas Gerais - FAPEMIG, pelo financiamento do projeto de pesquisa; e ao Conselho Nacional de Desenvolvimento Científico e Tecnológico-CNPq, pela concessão da bolsa de Iniciação Científica à primeira autora.

\section{REFERÊNCIAS}

ARATO, H. D.; MARTINS, S. V.; FERRARI, S. H. S. Produção e decomposição de serapilheira em um Sistema Agroflorestal implantado para recuperação de área degradada em Viçosa-MG. Revista Árvore, v.27, n.5, p.715-721, 2003.
BALIEIRO, F. C. et al.Acúmulo de nutrientes na parte aérea, na serapilheira acumulada sobre o solo e decomposição de filódios de Acacia mangium Willd. Ciência Florestal, v.14, n.1, p.59-65, 2004.

BERNARDINO, F. S.; GARCIA, R. Sistemas Silvipastoris. Pesquisa Florestal Brasileira, n.60, p.77-87, 2009.

CALDEIRA, M. V. W. et al.Quantificação de serapilheira e de nutrientes em uma Floresta Ombrófila Densa. Ciências Agrárias, v.29, n.1, p.53-68, 2008.

CASTRO, C. R. T.; GARCIA, H.; COUTO, L. Sistemas Silvipastoris no Brasil: potencialidades e entraves. Revista Árvore, v.20, n.4, p.575-582, 1996.

COSTA, K. A. P. et al. Doses e fontes de nitrogênio em pastagem de capim-marandu. I Alterações nas características químicas do solo. Revista Brasileira de Ciência do Solo, v.32, n.4, p.1591-1599, 2008.

DANIEL, O. et al. Proposta de um conjunto mínimo de indicadores biofísicos para o monitoramento da sustentabilidade em sistemas agroflorestais. Cerne, v.7, n.1, p.41-53, 2001.

\section{DEPARTAMENTO NACIONAL DE} METEOROLOGIA- DNMET. Normais limatológicas (1961-1990). Brasília: SPI/ EMBRAPA, 1992. 84p.

DIAS, P. F. et al. Influência de áreas sob a copa de leguminosas arbóreas na produção de fitomassa e nutrientes do capim Survenola. Revista Agricultura Tropical, v.9, n.1, p.102-114, 2006.

DIAS, P. F. et al. Transferência do N fixado por leguminosas arbóreas para o capim Survenola crescido em consórcio. Ciência Rural, v.37, n.2, p.352-356, 2007.

FORRESTER, D. I.; BAUHUSA, J.;KHANNA, P. K.Growth dynamics in a mixed-species plantation of Eucalyptus globulus and Acacia mearnsii. Forest Ecology and Management,v.193, n.1-2, p.81-95, 2004.

Revista Árvore, Viçosa-MG, v.37, n.3, p.409-417, 2013 
FORRESTER, D. I. et al. Mixed-species plantations of Eucalyptus with nitrogen-fixing trees: A review. Forest Ecologyand Management,v.233, n.2-3, p.211-230, 2006.

GALZERANO, L.; MORGADO, E. Influência do Nitrogênio na produção e qualidade do capim Tifton 85 (Cynodon spp.). Revista Eletrônica de Veterinária, v.8, n.2, p.1-8, 2007.

GARAY,I. et al.Comparação da matéria orgânica e de outros atributos do solo entre plantações de Acacia mangiume Eucalyptus grandis. Revista Brasileira de Ciência do Solo, v.27, n.4 p.705-712, 2003.

GARCIA, R.; TONUCCI, R.G.; GOBBI, K.F. Sistemas Silvipastoris: uma integração pasto, árvore e animal. In: OLIVEIRA NETO, S. N. et al. (Org.) Sistema Agrossilvipastoril Integração lavoura, pecuária e floresta. Viçosa, MG: Sociedade de Investigações Florestais, 2010.p.123-166.

JARAMILLO-BOTERO, C. et al. Produção de serapilheira e aporte de nutrientes de espécies arbóreas nativas em um sistema agroflorestal na Zona da Mata de Minas Gerais. Revista Árvore, v.32, n.5, p.869-877, 2008.

KHANNA,P. K. Nutrient cycling under mixedspecies tree systems in Southeast Asia. Agroforestry Systems,v.38, p.99-120, 1998.

KLEINPAUL, I. S. et al. Plantio misto de Eucalyptus urograndis e Acacia mearnsii em Sistema Agroflorestal: I - produção de biomassa. Ciência Florestal, v.20, n.4, p.621-627, 2010 .

LACLAU, J. P. et al. Mixed-species plantations of Acacia mangium and Eucalyptus grandis in Brazil.Growth dynamics and aboveground net primary production. Forest Ecology and Management, v.255, n.12, p.3905-3917, 2008.

LIMA, S.S. et al. Teores de nutrientes da serapilheira e do solo sob sistema agroflorestal em área de transição no norte do Piauí. Revista Brasileira de Agroecologia, v.2, n.2, p.1034-1037, 2007.

MACEDO, M. C. M. Degradação de pastagens: conceitos, alternativas e métodos de recuperação. Informe Agropecuário, v.2, n.226, p.36-42, 2005.

Revista Árvore, Viçosa-MG, v.37, n.3, p.409-417, 2013
MARQUES, T. C. L. L. S.M. et al. Envolvimento de dióxido de carbono e mineralização de nitrogênio em Latossolo Vermelho-Escuro com diferentes manejos. Pesquisa Agropecuária Brasileira, v.35, n.3, p.581-589, 2000.

NASCIMENTO, M. C. et al. Uso de imagens do sensor ASTER na identificação de níveis de degradação em pastagens. Revista Brasileira de Engenharia Agrícola e Ambiental, v.10, n.1, p.196-202, 2006.

PACIULLO, D. S. C. et al. Características produtivas e qualitativas de pastagem de braquiária em monocultivo e consorciada com estilosantes. Pesquisa Agropecuária Brasileira, v.38, n.3, p.421-426, 2003.

PACIULLO, D. S. C. et al. Morfofisiologia e valor nutritivo do capim-braquiária sob sombreamento natural e a sol pleno. Pesquisa Agropecuária Brasileira, v.42, n.4, p.573-579, 2007.

PERON, A. J.; EVANGELISTA, A. R. Degradação de pastagens em regiões de cerrado. Ciência e Agrotecnologia, v.28, n.3, p.655-661, 2004.

POWER,I.L.; THORROLD, B.S.;BALKS, M.R.Soil properties and nitrogen availability in silvopastoral plantings of Acacia melanoxylon in North Island, New Zealand. Agroforestry Systems, v.57, n.3, p.225-237, 2003.

SÁNCHEZ, S.; HERNÁNDEZ, M.; SIMÓN, L. Efecto del sistema silvopastoril en la fertilidad edáfica en unidades lecheras de la empresa Nazareno. Pastos y Forrajes, v.26, n.2, p.131-136, 2003.

SANTOS, R.S.M. et al.Componentes da parte aérea e raízes de pastagens de Brachiaria spp. em diferentes idades após a reforma, como indicadores de produtividade em ambiente de cerrado. Pesquisa Agropecuária Tropical, v.37, n.2, p.119-124, 2007.

SANTOS, M. V. Renovação de pastagem em plantio direto e sistema agrossilvipastoril. 141f. Tese (Doutorado em Zootecnia) - Universidade Federal de Viçosa, Viçosa, MG, 2009. 
SCHUMACHER, M.V.et al. Retorno de nutrientes via deposição de serapilheira em um povoamento de acácia-negra (Acacia mearnsii De Wild.) no estado do Rio Grande do Sul. Revista Árvore, v.27, n.6, p.791-798, 2003.

SIERRA, J.; DAUDIN, D. Limited 15N transfer from stem-labeled leguminous trees to associated grass in an agroforestry system. European Journal of Agronomy, v.32, n.3, p.240-242, 2010.

TEDESCO, M. J.; GIANELLO, C.; BISSANI, C. A. Análise de solo, plantas e outros materiais. 2.ed. Porto Alegre: Universidade Federal do Rio Grande do Sul, 1995.174p.

VEZZANI, F. M.; TEDESCOM. J.; BARROS N. F. Alterações dos nutrientes no solo e nas plantas em consórcio de eucalipto e acácia-negra.

Revista Brasileira de Ciência do Solo, v.25, n.1, p.225-231, 2001.
XAVIER, D. F. et al. Melhoramento da fertilidade do solo em pastagem de Brachiaria decumbens associada com leguminosas arbóreas. Pasturas Tropicales, v.25, n.1, p.23-26, 2003.

XAVIER, D. F. et al. Dinâmica da serapilheira em pastagens de braquiária em sistema silvipastoril e monocultura. Pesquisa Agropecuária Brasileira, v.46, n.10, p.1214-1219, 2011.

WENDLING, I. J. Produtividade e valor nutritivo do capim-braquiária em sistemas silvipastoris com Eucalipto e Acácia adubados com nitrogênio. 2011. 95f.Tese (Doutorado em Zootecnia) - Universidade Federal de Viçosa, Viçosa, MG, 2011.

WILDIN, J. H. Trees for forage systems in Australia. Rockhampton: Queensland Department of Primary Industries, 1990. 43p. 
